\title{
Familial Hypocalciuric Hypercalcemia secondary to a novel mutation causing severe hypercalcemia.
}

\author{
Natasha Shrikrishna1 ${ }^{1}$ S Mohamed ${ }^{2}$, Maeve Middleton ${ }^{2}$, Emma McCann ${ }^{3}$. Aye Nyunt ${ }^{1}$, Gayatri Sreemantula1 \\ Stephen Wong ${ }^{1}$ \\ Department of Diabetes and Endocrinology, Glan Clwd Hospital, Rhyl, Denbighshire, LL18 5 UJ \\ Cardiff University, Cardiff, Wales, CF10 $3 A T$ \\ Department of Clinical Genetics, Glan Clwd Hospital, Rhyl, Denbighshire, LL18 5UJ
}

\begin{abstract}
Introduction
The calcium sensing receptor (CASR) is a class $3 \mathrm{G}$ protein which helps maintain calcium homeostasis. This occurs by regulating parathyroid secretion and calcium metabolism in the kidneys. CASR works on the MAP- kinase and CAMP signalling pathways.

Mutations occurring in this protein can result in a dysfunction of the set point for calcium sensing causing a hyper or hypocalcemic disorder. The spectrum of phenotypes caused by the mutation varies leading to a benign disorder such as Familial hypocalciuric hypercalcemia (FHH) extending to a severe life threatening disorder such as neonatal severe hyperparathryoidism (NSHPT).

NSHPT causes hypercalcemia and high PTH in infants requiring immediate treatment. These infants develop poor feeding, dehydration and skeletal demineralisation. Infants with a homozygous CASR mutation are critically ill due to a calcium leve greater than 4nM whereas hetrozygous NHPT patients have a lower serum calcium level and is picked up during routine blood test as an infant. In these cases a parthryoidectomy is used to manage these patients. Autosomal dominant hypocalcemia (ADH) is a condition alsc caused by mutations in the CASR protein causing hypocalcemia with a low to normal PTH.

FHH is a benign autosomal dominant condition. For a diagnosis of FHH to be made, the presence of a mutation in either the CASR, GNA11 (type $2 \mathrm{FHH}$ ) or AP2S1 should be found. The CASR protein is expressed in many tissues, however, patients are commonly asymptomatic and the condition is shown by a high level of calcium, PTH and a normal renal function. The difference between FHH and primary hyperparathyroidism is that there is a low urinary excretion in $\mathrm{FHH}$.

This case shows a family in which the three brothers have a novel mutation causing hypercalcemia, however, leading to a variety of symptoms.
\end{abstract}

\section{Case}

A 20-year-old man was being investigated for a non-epileptic seizure and an incidental finding of a serum calcium $3.21 \mathrm{mmol} / \mathrm{L}$ was found. On further questioning, he had been complaining of muscle aches, joint pains and fatigue. Subsequent investigations showed paired PTH 2.14.6nmol/L, PTHrP $<0.7$, calcium excretion index $0.006-0.0006$ and $24 \mathrm{hr}$ urine calcium of $1.6 \mathrm{mmol} / 24 \mathrm{hr}$. His sestambi scan revealed no parathyroid adenoma and his DEXA scan showed osteopenia.

A detailed family history was obtained indicating his mother had suffered from renal stones secondary to hypercalcemia in the past. He had three bothers and one sister and his siblings were also tested and $i$ was revealed that two of his brothers had hypercalcemia. This can be shown in table 1.

Brothers 1,2,4 all have hypercalcemia, however, interestingly their symptoms vary with each each brother. Brother 1 is asymptomatic whereas brother 2 and 4 suffer with bone aches and paraesthesia.

Brother 1 also seems to be more affected by his symptoms than brother 4. Genetic testing in all three have revealed the same two mutations for each brother

\section{Heterozygous for c.553C>T (p.Arg185X) \\ Heterozygous for unclassified variant c.1375C $>A$ (p.GIn459Lys)}

This second mutation is an unknown variant, which has not been reported in literature. Genetic testing of the parents has shown one altered copy gene in each. Cinacalcet has been used for the brother 1 and 4, with brother 4 showing benefit. However, brother 1 despite treatment still suffers with severely with symptoms even though his calcium despite treatment is normal (table 2). In this case, would the a parthyroidectomy be more beneficial at managing these cases of $\mathrm{FHH}$.
Table 1

\begin{tabular}{|l||l|l|l||l|l||}
\hline Patient & $\begin{array}{l}\text { Parathyroid } \\
\text { hormone } \\
\text { (nmol/L) }\end{array}$ & $\begin{array}{l}\text { Adjusted } \\
\text { calcium } \\
\text { (nmol/L) }\end{array}$ & $\begin{array}{l}\text { Phosphate } \\
\text { (nmol/L) }\end{array}$ & $\begin{array}{l}\text { Alkaline } \\
\text { phosphatase } \\
\text { (IU/L) }\end{array}$ & $\begin{array}{l}\text { Urine } \\
\text { calcium } \\
\text { creatinine } \\
\text { ratio } \\
\text { (mmol/mmol) }\end{array}$ \\
\hline Dad & 3.3 & 2.57 & 0.90 & 74 & 0.25 \\
\hline Mum & 3.8 & 2.52 & 1.09 & 94 & 0.17 \\
\hline Daughter & 3.5 & 2.51 & 1.04 & 100 & 0.30 \\
\hline Brother 1 & 5.3 & 3.53 & 0.65 & 71 & 0.03 \\
\hline Brother 2 & 3.5 & 3.60 & 0.55 & 91 & 0.25 \\
\hline Brother 3 & 2.6 & 2.30 & 1.30 & 89 & 0.26 \\
\hline Brother 4 & 4.1 & 3.46 & 0.36 & 59 & 0.10 \\
\hline
\end{tabular}

Table 2

\begin{tabular}{|l||l||l||l|}
\hline Patient & $\begin{array}{l}\text { Adjusted } \\
\text { calcium } \\
\text { (nmol/L) }\end{array}$ & $\begin{array}{l}\text { Adjusted calcium } \\
\text { post Cinacalcet } \\
(\mathrm{nmol} / \mathrm{L})\end{array}$ & Symptoms \\
\hline Brother 1 & 3.53 & 2.56 & $\begin{array}{l}\text { Severe } \\
\text { symptoms }\end{array}$ \\
\hline Brother 2 & 3.60 & 2.76 & Asymptomatic \\
\hline Brother 4 & 3.46 & 2.78 & Mild syptoms \\
\hline
\end{tabular}

\section{Discussion}

This case shows three brothers who have type $1 \mathrm{FHH}$. However, in this kindred, there is a novel mutation in which two mutations affect the CASR gene leading to a different scale of symptoms for each. Diagnosing FHH compared to primary hyperparthyoidism is oased on the presence of long term hypercalcemia, strong family history, the inability to detect an adenoma on imaging and the presence of a mutation in genetic testing.

FHH usually requires no treatment. However, there are some cases of FHH who are symptomatic, suffering from recurrent pancreatitis, muscle cramps and paraesthesia. In these patients, treatment with Cinacalcet, a calcimimetic, has shown benefit.

Cinacalcet causes a decrease in PTH preceding the decline in serum calcium which has been shown to decline by $0.4-1 \mathrm{mg} / \mathrm{kg} / \mathrm{d}$ after daily doses of cinacalcet. As can be seen in the table 1, despite his calcium being normal with Cinacalcet, brother 1 still seems to be severely affected by symptoms.

In this case, there are two mutations affecting these brothers, and therefore, initial treatment with Cinacalcet may not effectively manage these brothers. Therefore, should we consider a parthyroidectomy to manage these patients to prevent long term complications. Parathyroidectomy is successful in lowering PTH and calcium levels. Subtotal and total parathyroiectomy are performed in infants with NSHPT, however, there are less chance of recurrence with total parathyroidectomy.

Reference

Mayr B, Schnabel D, Dorr HG, Schofl C. Gain and loss of Function Mutations of the Calcium-Sensing Receptor and associated Proteins: Current treatment concepts. EJE 2015:151028 